\title{
Article
}

\section{Epistemic perspective and online epistemic processing of evidence: Developmental and domain differences}

Iordanou, Kalypso, Muis, Krista and Kendeou, Panayiota

Available at http://clok.uclan.ac.uk/22804/

Iordanou, Kalypso ORCID: 0000-0001-5930-9393, Muis, Krista and Kendeou, Panayiota (2019) Epistemic perspective and online epistemic processing of evidence: Developmental and domain differences. Journal of Experimental Education, 87 (4). pp. 531-551. ISSN 0022-0973

It is advisable to refer to the publisher's version if you intend to cite from the work. http://dx.doi.org/10.1080/00220973.2018.1482857

For more information about UCLan's research in this area go to http://www.uclan.ac.uk/researchgroups/ and search for <name of research Group>.

For information about Research generally at UCLan please go to http://www.uclan.ac.uk/research/

All outputs in CLoK are protected by Intellectual Property Rights law, including Copyright law. Copyright, IPR and Moral Rights for the works on this site are retained by the individual authors and/or other copyright owners. Terms and conditions for use of this material are defined in the policies page.

\section{CLoK}

Central Lancashire online Knowledge www.clok.uclan.ac.uk

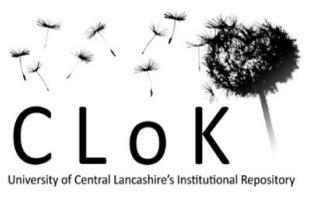


Running head: EPISTEMIC PERSPECTIVE AND ONLINE EPISTEMIC PROCESSING OF EVIDENCE

Epistemic perspective and online epistemic processing of evidence: Developmental and domain differences

Kalypso Iordanou ${ }^{\mathrm{a}}$, Krista R. Muis ${ }^{\mathrm{b}}$ and Panayiota Kendeou ${ }^{\mathrm{c}}$

${ }^{a}$ School of Sciences, University of Central Lancashire Cyprus

${ }^{\mathrm{b}}$ Department of Educational and Counselling Psychology, McGill University

${ }^{\mathrm{c}}$ Department of Educational Psychology, University of Minnesota

Cite as:

Iordanou, K., Muis, K. R., \& Kendeou, P., (forthcoming, 2018). Epistemic perspective and online epistemic processing of evidence: Developmental and domain differences. Journal of Experimental Education.

Corresponding author:

Kalypso Iordanou, Ph.D.

UCLan Cyprus

12-14 University Avenue, Pyla, 7080 Larnaka, Cyprus

Tel: +35724812121

Fax: +35724812120

Email: KIordanou@uclan.ac.uk 


\title{
Epistemic perspective and online epistemic processing of evidence: Developmental and domain differences
}

\begin{abstract}
Relations between epistemic perspective and online epistemic processing of evidence when reading a text were examined. Thirty-seven young adolescents and 24 graduate university students were asked to read and think-aloud with two texts, one in the history domain and the other in the science domain. Participants also completed a prior-knowledge test and an instrument assessing their epistemic perspective. Results showed that participants who exhibited an evaluativist epistemic perspective and high prior-knowledge used the epistemic standard of scientific research more than participants who held non-evaluativist epistemic perspective. Furthermore, an age-related developmental difference was observed, with adults using the epistemic standard of scientific research more than young adolescents. Domain differences were observed in both participants' epistemic perspective and online epistemic processing. Participants overall engaged in online epistemic processing of evidence more in the history topic than in the science topic.
\end{abstract}

Key words: epistemic cognition; epistemic perspective; evidence; domain differences; developmental differences. 


\section{Introduction}

Engagement in critical evaluation is considered one of the most desirable educational outcomes in the $21^{\text {st }}$ century (NGSS Lead States, 2013). Critical evaluation is important for citizens who are not mere consumers of information but carefully weigh arguments before adopting or changing beliefs. Critical evaluation while reading a text involves evaluation of the arguments that are included in the text, such as examination of the claims and the evidence that support them (Walton, 1989). Evaluation of evidence has been examined in the literature under distinct lines of research. These include (1) argumentation, which focuses on argument construction, (2) argument evaluation, which focuses on comprehension and evaluation of arguments in the context of reading, and (3) epistemic cognition, which refers to "how people acquire, understand, justify, change, and use knowledge in formal and informal contexts" (Greene, Sandoval, \& Bråten, 2016, p. 2).

Evaluation can be cognitive or metacognitive in nature, depending on the object examined. According to Barzilai and Zohar (2014), "evaluation is cognitive when its object is the correctness or truth of specific knowledge claims and is metacognitive when its object is the thinking processes and standards used in cognitive evaluation of knowledge claims" (p. 20). Like Barzilai and Zohar (2014), we view evaluation of claims and evidence in a text as an epistemic cognitive process, falling under the general umbrella term of epistemic cognition. A large research literature indicates that individuals have difficulty engaging in critical evaluation of evidence (e.g., Iordanou \& Constantinou, 2014; Sandoval \& Millwood, 2005). One factor that might affect individuals' engagement in evaluation is their epistemic perspective, which reflects individuals' metacognitive knowledge, namely their 'knowledge, beliefs, ideas, and theories regarding the nature of knowledge and knowing." (Barzilai \& Zohar, 2014, p. 20). Although 
research thus far has focused on examining relations between individuals' epistemic perspective and use of evidence in the context of argument production (Kuhn, 1991), knowledge regarding relations between individuals' epistemic perspective and “online” epistemic processing, in particular in relation to evaluation of evidence, is very limited.

Another factor that might also play a role in epistemic processing of evidence is individuals' age-related developmental level. For example, earlier studies have shown a quantitative, as well as a qualitative growth in cognitive and metacognitive skill with age (Kitsantas \& Zimmerman, 2002; Roderer \& Roebers, 2014; van der Stel \& Veenman, 2010; Veenman, Wilhelm, \& Beishuizen, 2004). Yet, we do not have empirical evidence regarding potential age differences in the epistemic processing of evidence. A third factor might be the domain in which the evidence is presented. Indeed, the question of whether epistemic cognition is domain specific or domain general remains an open one (Greene et al., 2016; Muis, Bendixen, \& Haerle, 2006). In addition, differences have been reported in individuals' epistemic cognition about evidence between the social and the science domains (Iordanou, 2016), which might affect individuals' epistemic processing of evidence in the social and science domains, respectively.

As information rapidly increases and becomes more easily accessible via the internet, it is imperative to better understand how these factors, epistemic perspective, age, and domain, influence the evaluation of evidence (Sinatra, Kienhues, \& Hofer, 2014). To address this issue, we examine the influence of epistemic perspective on young adolescents' and adults' engagement in evaluation of evidence during reading in history and science using a think-aloud approach. We examine online epistemic processing of evidence, that is individuals' reflections about evidence during reading with an emphasis on evidence's credibility, persuasiveness and its 
role in the context of an argument. In doing so, we draw on the relevant theoretical frameworks of epistemic cognition and its relation to age and domain differences.

\subsection{Epistemic cognition}

Within the epistemic cognition literature, there are two main theoretical frameworks: the multidimensional approach and the developmental approach. The multidimensional approach conceptualizes epistemic cognition as a system of more-or-less independent beliefs (Hofer \& Pintrich, 1997; Hofer, 2004; Schommer, 1994), whereas the developmental approach proposes a unidimensional developmental progression of epistemic cognition (King \& Kitchener, 1994; Kuhn, 1991). Several of the multidimensional frameworks that have been proposed share commonalities that can be categorized along four dimensions (Hofer \& Pintrich, 1997). Two of these dimensions, (1) certainty of knowledge and (2) simplicity of knowledge, refer to the nature of knowledge. The other two dimensions, (3) source for knowing and (4) justification for knowing, refer to the nature of knowing.

Recently, Chinn et al. (2011) proposed an expansion of the dimensions of epistemic cognition. For example, Chinn et al. suggested a finer-grained analysis of students' beliefs about justification for knowing, focusing particularly on justifications based on evidence. For evidence, they proposed a deeper analysis of individuals' specific evidential standards, such as what kind of evidence they consider as good evidence in a particular context. Our present work addresses this recommendation by examining individuals' spontaneous evaluations of evidence in the context of a particular text.

In the present study, we adopt the developmental approach of epistemic cognition because we are particularly interested in examining age-related developmental differences in epistemic cognition. According to this approach, the developmental task that underlies the 
progression toward an evaluativist epistemic perspective, (e.g., that knowledge is actively constructed instead of passively received by authority figures) is the coordination of the subjective and objective dimensions of knowing (Kuhn, Cheney, \& Weinstock, 2000). In this context, one's epistemic perspective progresses from the absolutist level, to the multiplist level and then to the evaluativist level (Kuhn et al., 2000). In the absolutist level, the objective dimension of knowing dominates. Knowledge is conceived as an objective, external entity, which is knowable with certainty. In the mutliplist level, knowledge is no longer considered an object that is located in the external world, but a product of the human mind which is located in one's self. At the multiplist level, the uncertain and subjective nature of knowledge come to the foreground and dominates one's view of knowledge. At the evaluativist level, a balance is achieved between the objective and subjective dimensions of knowledge (Kuhn et al., 2000). A constructivist epistemic perspective involves the coordination of the subjective and objective dimensions of knowledge. Through evaluation, the position that is better supported by argument and evidence would be declared as the position that has more merits compared to alternative positions (Kuhn et al., 2000). Empirical studies, employing either the multidimensional or developmental approach, show evidence that one's epistemic perspective changes with age and varies across domains. We discuss age-related developmental and domain differences in epistemic perspective next.

\subsection{Age-related Developmental and Domain Differences}

The issue of domain specificity is an important issue on research in epistemic cognition (Greene et al., 2016). At the heart of the issue is to what extent beliefs vary across domains through the developmental trajectory and at what level of specificity beliefs should be considered across this trajectory (Muis et al., 2006). Are there age-related developmental differences in 
levels of specificity? Given that the domain-specificity and even topic-specificity of epistemic cognition has been demonstrated in different empirical studies (Iordanou, 2010; Kuhn, et al., 2000; Muis, Trevors, Duffy, Ranellucci, \& Foy, 2016; Strøms $\varnothing$, Bråten, \& Britt, 2011), this is clearly an important consideration for research on epistemic cognition. For example, Muis et al. (2016) found that secondary, college, undergraduate and graduate-level students held distinct epistemic cognitions about mathematics compared to psychology and everyday life. In another study, Kuhn et al. (2000) found differences in middle school students', adolescents' and adults' epistemic cognition across different domains such as the physical science, social science and aesthetic domains.

Epistemic cognition varies not only by context and content (Bråten, Britt, Strøms $\varnothing, \&$ Rouet, 2011; Kuhn et al., 2000), but also by age. There is evidence that an evaluativist epistemic perspective is more common among adults than children (Iordanou, Kendeou, \& Beker, 2016; Kuhn, Iordanou, Pease, \& Wirkala, 2008; Muis et al., 2016). For example, in Kuhn, Iordanou, et al.'s (2008) study, evaluativist epistemic perspective was more prevalent among teachers than among $6^{\text {th }}$ grade students. Pertinent to this study is evidence supporting an association between an evaluativist epistemic perspective and the development of advanced thinking skills and learning (Mason, Ariasi \& Boldrin, 2011; Muis \& Franco, 2010; Stømsø, et al., 2011). Yet, this line of research does not inform our understanding of how epistemic perspective relates to learning and reasoning (Bromme, Pieschl, \& Stahl 2010). An association between epistemic perspective and online epistemic processing has been proposed to explain the relation between epistemic cognition and learning, which is discussed below.

\subsection{Epistemic Perspective and Online Epistemic Processing}


To explain how epistemic cognition supports thinking and learning, some researchers proposed an association between epistemic beliefs and epistemic processing (Hofer, 2004; Muis, 2007; Muis \& Franco, 2010; Muis, Franco, \& Gierus, 2011).

1.3.1. Muis' model. In Muis’s model (2007) (1) epistemic beliefs constitutes one component of the cognitive and affective conditions of a task; (2) epistemic beliefs influences the learning standards students set when goals are produced (e.g., standards for comprehension; “Do I know this?”); (3) epistemic beliefs translates into epistemic standards (e.g., standards about knowledge and knowing; "How do I know this?" or "Do I believe this?") that serve as inputs to online epistemic processing; and, (4) self-regulated learning may play a role in the development of epistemic beliefs. Importantly, Muis proposed that epistemic beliefs influence the types of goals an individual sets for learning, the plans made for carrying out the task, the types of strategies used during learning, and how and to what extent epistemic processes are enacted. For example, a goal is modeled as a multifaceted profile of information (Butler \& Winne, 1995) and each standard in the profile is used as a basis to compare the products created when engaged in the activity. The product is compared to the goal's criteria via online epistemic processing. During learning, individuals evaluate the successes or failures of products created for the task, or perceptions about the self or context. Products created during learning are compared to the standards set via online epistemic processing. As such, key to evaluation is online epistemic processing.

1.3.2. Kuhn's model of epistemic cognition. In Kuhn's (2001) model, epistemological understanding supports the process of knowing. Epistemological understanding determines whether knowing strategies, such as inquiry, analysis, inference and argument are executed. In particular, epistemological understanding informs intellectual values - that deal with questions 
such as "Is there a point to arguing?" - and intellectual values, in turn, affect the disposition to apply strategies.

Muis' model focuses on epistemic beliefs, whereas Kuhn's model focuses on epistemological understandings and suggests that individuals have tacit theories or perspectives, which incorporate these understandings (Barzilai \& Weinstock, 2015). In the present work, given the different terminology used in the field of epistemic cognition, to avoid confusion (Greene, Sandoval, \& Bråten, 2016) we use the term epistemic perspective throughout this paper, which is more reflective of the developmental approach.

The relation between epistemic perspective and epistemic processing has attracted researchers' interest recently, as it is reflected in the special issue on this topic which was published in "Metacognition and Learning" (2010). For example, Mason, Boldrin and Ariasi (2010) examined relations between the metacognitive activation of epistemic cognition during learning from the internet and individuals' domain-specific self-reported epistemic perspective. Mason and colleagues examined middle school students' self-reported epistemic perspective and their responses to interview questions about their searches on the Web. Results showed that beliefs in the complexity and tentativeness of knowledge correlated with reflections about the justification and uncertainty of knowledge. Similar findings have been reported by Strømsø and Bråten (2010) who found that undergraduate students who believed that knowledge claims need to be checked against other knowledge sources were more likely to report self-regulatory strategies of planning, monitoring, and regulation when using the Internet compared to students who believed that knowledge claims can be accepted without critical examination.

\subsubsection{Reflection on the methodological approaches employed in previous studies to} study epistemic perspective and epistemic processing. The studies described in section 1.2.2., 
among others (e.g., Lin, Liang, \& Tsai, 2012; Muis \& Franco, 2010; Muis, Kendeou, \& Franco, 2011; Stahl, Pieschl, \& Bromme, 2006), suffer from the same limitations as studies that explored relations between epistemic perspective and learning: They employed self-report measures to assess epistemic processing, which have notable psychometric problems (see Winne, JamiesonNoel, \& Muis, 2002). Furthermore, research examining relations between epistemic perspective and epistemic processing examined epistemic processing after engagement in an activity, employing offline methods through retrospective interviews (e.g., Mason, et al., 2010) or questionnaires in which participants reported the frequency of engagement in epistemic processing in a particular course (Muis \& Franco, 2010). Research examining epistemic processing using online methods, that is during engagement in an activity (e.g., Bannert \& Mengelkamp, 2008), is limited (Hofer \& Sinatra, 2010). In the present work, we examine how individuals' epistemic perspective influences the online epistemic processing of justification during reading of a text.

Note that the focus of the present work is on online epistemic processing of justification of knowledge claims embedded within a text, rather than on abstract judgments regarding justification of knowledge or on justification of the trustworthiness of a text as a whole, which has been studied in previous work. For example, Strømsø et al. (2011) studied relations between undergraduate students' topic-specific epistemic cognition and their judgments of the trustworthiness of a science text and a newspaper article, as well as the criteria they used to judge trustworthiness, through paper and pencil questionnaires. Results showed that students who believed that claims should be critically evaluated considered the science text as more trustworthy and reported that they used the criteria of their own opinion, author and content more than students who believed in relying on their own experiences for judging the trustworthiness of 
the source. Bråten and colleagues also found a relation between students' prior knowledge and judgments of trustworthiness (Bråten, Strøms $\varnothing, \&$ Salmerón, 2011). Relations have also been reported between justification of knowledge claims and memory of arguments when undergraduate students read articles presenting inaccurate arguments (Braasch, Bråten, Britt, Steffens, \& Strøms $\varnothing, 2014)$. In particular, justification of knowledge claims by personal opinion was negatively correlated with memory of arguments, whereas justification of knowledge by appealing to authority was positively related with memory of arguments.

In another study, Ferguson and Bråten (2013) found that less knowledgeable secondary school students exhibited stronger beliefs in personal justification, whereas among more knowledgeable students some exhibited beliefs in justification by authority and others in justification by multiple sources. As the authors noted, a limitation of these studies is that "presenting participants with descriptions of each text, including source relevant information, and then explicitly asking them to rate the trustworthiness of each text as well as the importance of prelisted criteria, might have resulted in source evaluation not reflecting what participants would spontaneously do during normal reading" (Bråten et al., 2011, p. 190). According to Britt, Richter and Rouet (2014) "more research is needed to better understand the conditions under which readers will spontaneously and strategically evaluate content, what criteria they use, and how this is affected by the situation and materials" (p. 118). Taken together, there are a number of limitations from previous work that need to be addressed to better understand how epistemic cognition relates to learning and reasoning. Our study addresses the limitations observed in previous research and contributes to understanding how individuals evaluate evidence during reading, examining the epistemic criteria they use and how evidence evaluation varies by age and knowledge domain. 


\subsection{The Present Study}

In the present study, we examine how individuals of varying ages (i.e., adolescents and adults) with different epistemic perspectives (i.e., absolutists, multiplists, evaluativists) engage in epistemic processing of evidence moment-by-moment during reading of texts, across two different domains (i.e., history and science). We examine online epistemic processes using a think-aloud methodology. The think-aloud methodology has been used in previous studies to explore relations between epistemic cognition and learning strategies when reading and problem solving (Greene, Yu, \& Copeland, 2014; Hofer, 2004; Mason, Ariasi, \& Boldrin, 2011; Muis, 2008). We move beyond these studies by examining on-line epistemic processing focusing particularly on evidence. According to Chinn et al., (2011) "To understand actual learning processes, one needs measures that probe students' more specific evidential standards" (p. 154). The think-aloud methodology is a measure that has the potential to reveal how participants approach evidence in a particular context.

Our first research question was: Do individuals at different developmental levels of epistemic perspective and different prior knowledge differ in the "online" epistemic processing of evidence that they engage in when reading a text? Although there is evidence for an agerelated developmental progression in epistemic perspective (Kuhn, Iordanou, et al., 2008; Muis et al., 2016), our knowledge regarding this progression is limited. To address this gap in the literature, we examined a group of young adolescents and a group of adults. We hypothesized that evaluativists (Kuhn et al., 2000), who consider that knowledge is not certain and one view could be better than others, will engage in more epistemic processing of evidence than absolutists and multiplists (Hypothesis 1). Evaluation would be meaningless for absolutists, who consider that knowledge is certain and accessible from the external world, or for multiplists, who 
consider knowledge as totally subjective and therefore approach all views as equally right. We further hypothesized that more epistemic processing would be observed for older compared to younger individuals (Hypothesis 2), given the evidence for better learning skills with increasing age (Roderer \& Roebers, 2014; van der Stel \& Veenman, 2010). We also included a test of prior knowledge to examine whether and how prior knowledge might influence online epistemic processing of evidence, given that earlier studies yielded contradictory results regarding the relation between prior knowledge and epistemic processing (Bråten, Strøms $\emptyset$, \& Salmerón, 2011; Mason et al., 2010). Finally, we hypothesized that epistemic processing and prior knowledge would mediate the effect of age on epistemic processing (Hypothesis 3).

The second research question was: Are there domain differences in epistemic perspective and epistemic processing of evidence? Previous work showed that epistemic perspective is domain- and even topic-specific (Kuhn, Iordanou, et al., 2008; Muis et al., 2006). In particular, domain differences have been reported in individuals' epistemic knowledge regarding evidence. In Iordanou's (2016a) study, elementary school students considered scientific data as central for knowledge acquisition in the science domain, whereas in the social domain personal experience was considered as meeting sufficient evidential standards. Yet, our understanding of how individuals evaluate information in different domains is far from complete (Mills, 2013). To address this issue, we examined two different knowledge domains, the history and science domains. Based on previous research, providing evidence for domain-specificity of epistemic perspective (Kuhn et al., 2000), we hypothesized that participants would exhibit different epistemic perspectives across the history and the science domains. In terms of epistemic processing, we hypothesized that since participants tend to view knowledge in the social domain as more subjective, and therefore amenable to human interpretation than knowledge in the 
science domain (Iordanou, 2016a), they would engage in evaluation of evidence more in the history domain than in the science domain (Hypothesis 4).

\section{Method}

\subsection{Participants}

Sixty-one students from Cyprus, a small European country, participated. The sample of young adolescents $(N=37,23$ females) included 18 first- and second-year secondary school students (13-14 year-olds) and 19 fifth- and sixth-grade elementary school students (11-12 yearolds). Participants were randomly selected from public schools in a middle-class suburban area. The 24 graduate university students (mean age $=22$ year-olds; $N=20$ females) were first year students in a Master's program in Educational Psychology in a small private university, who participated as part of a course requirement. Three students did not participate in the think-aloud procedure of the history domain and were therefore excluded from the analysis of the history domain.

\subsection{Materials}

2.2.1. Epistemic perspective instruments. To assess participants' epistemic perspective in the history and science domains, the Livia and Fish problems (Kuhn, Iordanou, et al., 2008) were used. The Livia problem presented two contradictory accounts from two historians regarding the fictitious Fifth Livia war. The Fish problem presented two contradictory accounts from two scientists about the effect of eating fish on health. Participants were asked the same key questions in each case regarding (a) rightness - Can one view be more right than the other? and (b) the certainty of knowledge - b1. Could anyone ever be certain about what happened in the Fifth Livia war [about the consequences of eating fish on health]? b2. What would help us become more certain? 
2.2.2. History and science texts. Two short texts, one in the history domain and the other in the science domain, were used to engage students in learning. Each text presented two contradictory positions, along with supporting evidence for each position. The science domain text presented two contradictory reports about the causes of dinosaurs' extinction (Iordanou, 2010). One report claimed that dinosaurs were exterminated due to the collision of an asteroid with the Earth, whereas the other reported that dinosaurs gradually disappeared due to a series of giant volcanic eruptions. The text included 17 sentences (a total of 338 words). The history domain text presented two contradictory reports regarding the possible location of the historical island of Atlantis. One report claimed that the island of Atlantis was located in the Mediterranean Sea, whereas the other report claimed that it was located in the Atlantic Ocean. The text included 19 sentences (a total of 382 words).

2.2.3. Prior knowledge test. A prior knowledge test was developed and administered in the present study. The prior knowledge test consisted of two open-ended questions, which asked participants to write what they knew about the topics of the two texts that were used in the study. In particular, the first question was "What do you know about the lost island of Atlantis?" and the second questions was "What do you know about dinosaurs' extinction?"

\subsection{Procedure}

Participants participated in two 40-minute sessions. In the first session, participants completed the prior knowledge test and the two paper-and-pencil instruments assessing their epistemic perspective in the history and science domains, respectively. In the second session, participants were administered the history and science domain texts and were instructed to read and think-aloud. Participants were first trained to think-aloud with a short text and were prompted to think-aloud if they were silent for more than $4 \mathrm{~s}$. The order of presentation of the two 
texts, as well as the administration of the two instruments assessing epistemic perspective, was counterbalanced across participants. The first session was group-administered, whereas the second session was administered individually and audio-recorded.

\subsection{Coding Schemes}

2.4.1. Epistemic perspective. Responses to all three questions - regarding whether one scientist can be more right than the other, whether anyone could ever be certain about what happened in the scenario described, and what would help us become more certain - were used to identify each participant's epistemic perspective. The first two questions received Yes/No responses while the third one was an open-ended question. Participants' responses on the final question regarding what would help us to become more certain were coded based on the coding scheme developed by Kuhn, Iordanou, et al. (2008). Two coders, blind to the identity of the participants, coded all responses. Inter-rater reliability calculated with Cohen's kappa was 0.87 $(p<.001)$ for the Livia problem and $0.89(p<.001)$ for the Fish problem, indicating good interrater reliability. Disagreements were resolved through discussion. Participants were classified as absolutists if they responded that one view could be more right than the other and certainty was empirically possible via direct observation of data or by asking a scientist or could be possible if we could overcome some practical limitations. Participants were classified as multiplists if they reported that one view could not be more right than the other and certainty was not possible because of the subjective nature of human knowing. Finally, participants were classified as evaluativists if they reported that one view could be more right than the other and certainty was not possible, but it could be approachable through investigation, analysis and interpretation of evidence. Table 1 presents participants' epistemic perspective by age and domain. 
2.4.2. Think-aloud protocols. Participants' think-aloud episodes were transcribed verbatim and then parsed into clauses. Each clause was coded for evidence of epistemic processing (all participants' statements were coded). All responses were coded by two coders using the coding scheme described in the Appendix, and percentage of agreement was $90 \%$. Disagreements were resolved through discussion.

Epistemic processing statements were defined as statements about the evidence; this is in contrast to statements that constitute the evidence or are relevant to the content of the evidence. For example, the statement "in 1898, special equipment pulled to the surface of the Atlantic Ocean an islet which came from volcano land" was considered as evidence, whereas the statement "this evidence is not a proof that there was Atlantis" was considered as epistemic statement. Therefore, a first distinction was between epistemic processing statements and nonepistemic processing statements. Another novel distinction followed where epistemic processing statements were further distinguished between high and low epistemic processing statements, based on whether they employed the epistemic standard of scientific research or not. High epistemic processing statements included statements that focused on evidence itself and statements that focused on the evidence's role in the context of argument. The first case involved statements regarding evidence's credibility, persuasiveness and rightness, along with justification based on scientific research. Note that evidence's credibility in high epistemic processing was judged on whether there was an adequate amount of research supporting a piece of evidence or whether a particular piece of evidence was the product of research conducted with the scientific method. For example, statements such as "we need further research" and "so there are excavations and research studies which lead to this conclusion" were coded as high epistemic processing statements. The second case, which involved comments focusing on the evidence's 
role in the context of argument, included comments such as whether a particular piece of evidence supported the claim that it was supposed to support in the context of an argument. Low epistemic processing statements included comments regarding evidence's credibility that were justified by epistemic standards other than scientific research, including the rule of majority, first-hand experience or authority alone, without weighing other forms of evidence (Greene, Azevedo, Torney-Purta, 2008).

Comments regarding evidence's persuasiveness and rightness with no accompanied justification, general comments (e.g. this is interesting), and simple reference to personal opinion (e.g. I agree with this) and to personal knowledge (e.g. I know this) were coded as low epistemic processing statements. Table 2 includes example comments of all the aforementioned categories.

2.4.3. Prior knowledge test. Participants' responses in the prior knowledge test were coded based on the number of theories that participants provided to explain the phenomena. Each participant received two scores, one regarding his/her prior knowledge on the history domain topic and the other regarding his/her prior knowledge on the science domain topic. Participants received a score of 0 if they did not report any theory and 1 point for each new theory they reported. Scores ranged from 0 to 3 .

\section{Results}

\subsection{Preliminary Analysis}

Data were first screened for normality. The prior knowledge variable was normally distributed for both the history domain topic, $(M=.98, S D=.73, \min / \mathrm{max}=0 / 3$, skewness $=.35$, kurtosis $=-.08)$ and the science domain topic $(M=.69, S D=.79, \min / \mathrm{max}=0 / 3$, skewness $=.85$, kurtosis $=-.087$ ). Independent samples t-test showed that in the history domain there was no significant difference between evaluativists $(M=1.29, S D=.47)$ and multiplists $(M=1.00, S D=$ 
$.76), t(20)=.0 .85, p=.933$, between evaluativists and absolutists $(M=.78, S D=.80), t(44)=$ $1.940, p=.059$ or between multiplists and absolutists, $t(34)=.906, p=.371$. In the science domain, no statistically significant difference in prior knowledge was observed between evaluativists $(M=.85, S D=.67)$ and multiplists $(M=.90, S D=.97), t(38)=-.190, p=.851$, while statistically significant differences were observed between evaluativists and absolutists $(M$ $=.20, S D=.41), t(33)=3.304, p=.002$, and between multiplists and absolutists, $t(33)=2.900, p$ $=.007$. Statistically significant differences also were observed between adolescents and adults in both the history, $t(50)=-4.356, p<.001$ and science domain topics $t(53)=-7.686, p<.001$. As seen in Table 3, adults exhibited higher prior knowledge levels than adolescents in both the history and science domain topics respectively.

The epistemic processing statement variables were not normally distributed; skewness ranged from 2.64 to 5.67 , and kurtosis ranged from 7.52 to 34.66 and different transformations (arcsine, $\log$ ) were not sufficient to normalize the data. The results should therefore be interpreted with caution given that the data were not normally distributed, although this is normal with think aloud data. The majority of overall statements in both domains were non-epistemic statements. Notably, 59.17\% $(S D=39.08)$ and $68.76 \%(S D=35.45)$ of the overall statements in the history and science domains, respectively, constitute mere repetition of the evidence.

As seen in Table 1, the majority of participants, in both age groups and domains, were absolutists and multiplitists. Only one third of the participants held an evaluativist epistemic perspective.

\subsection{Epistemic Perspective, Age and Prior Knowledge as Predictors of Online Epistemic}

\section{Processing}


To examine our first research question, namely whether epistemic perspective, age and prior knowledge related to online epistemic processing of evidence, we conducted a multiple regression analysis ${ }^{1}$ on each type of epistemic statement in both the history and the science domains, utilizing epistemic statements as the criterion and age, epistemic perspective and prior knowledge as predictors. Epistemic perspective was represented by two dummy variables. Given the differences in number of utterances produced, percentages of usage were calculated for each participant in the amount of a particular type of processing out of total clauses, rather than frequencies.

\subsubsection{High online epistemic statements on credibility. When evaluativists served as}

the reference group for dummy variable, the regression model, was statistically significant for predicting use of high epistemic statements on evidence credibility in the history domain, $R^{2}=$ $.180, F(4,49)=2.692, p=.042$. None of the independent variables significantly predicted production of high epistemic statements on credibility (see Table 4a). With absolutists serving as the reference group or multiplists serving as the reference group, neither the regression model $\left(R^{2}\right.$ $=.154, F(4,49)=2.237, p=.079$, and $R^{2}=.142, F(4,49)=2.021, p=.106$, respectively $)$, nor the predictors were statistically significant (see Tables $4 \mathrm{~b} \& 4 \mathrm{c}$ ).

For the science topic, with evaluativists as the reference group in the dummy variables, the regression model was not statistically significant $\left(R^{2}=.077, F(4,50)=1.040, p=.396, \mathrm{~ns}\right)$ and none of the predictors were statistically significant. The regression models with absolutists as the reference group or multiplists as the reference group were not statistically significant $\left(R^{2}=\right.$ $.077, F(4,50)=1.040, p=.396$ and $R^{2}=.077, F(4,50)=1.040, p=.396$, respectively) and none of the individual predictors were statistically significant (see Tables $4 \mathrm{~b} \& 4 \mathrm{c}$ ).

\footnotetext{
${ }^{1}$ Although the sample size of the study was quite small $(N=38)$, it was sufficient to secure the statistical power of our findings; Tabachnick and Fidell (1996) recommend a minimum of 5 participants per independent variable.
} 
3.2.2. Low epistemic statements on credibility. The regression models for predicting use of low epistemic statements on evidence credibility, with evaluativists as the reference group, were not statistically significant in either the history domain $\left(R^{2}=.033, F(4,48)=.406, p\right.$ $=.803)$ or the science domain $\left(R^{2}=.047, F(4,50)=.610, p=.657\right)$. Similarly, the models using absolutists and multiplists as the reference group were not statistically significant $\left(R^{2}=.033\right.$, $F(4,48)=.406, p=.803 ; R^{2}=.033, F(4,48)=.405, p=.804$, for the history domain and $R^{2}=$ $.047, F(4,50)=.610, p=.657 ; R^{2}=.047, F(4,50)=.610, p=.657$, for the science domain, respectively). None of the independent variables in the models listed above significantly predicted production of low epistemic statements on credibility.

\subsubsection{High epistemic statements on evidence-claim relation. When evaluativists}

served as the reference group for dummy variable, a multiple regression showed that age, epistemic perspective, and prior knowledge explained a statistically significant amount of the variance in usage of epistemic statements on evidence-claim relation in the history domain, $R^{2}=$ $.395, F(4,49)=8.009, p<.001$. As shown in Table 5a, the two dummy variables representing epistemic perspective and Age were statistically significant individual predictors of usage of high epistemic statements on evidence-claim relation in the history domain, confirming Hypotheses 1

and 2. With absolutists serving as the reference group, the model was also statistically significant, $R^{2}=.404, F(4,49)=8.301, p<.001$. As shown in Table 5b, age and the dummy variable comparing absolutists and evaluativists were statistically significant individual predictors. With multiplists serving as the reference group, the model was again statistically significant, $R^{2}=.398, F(4,49)=8.110, p<.001$. Age and the dummy variable comparing evaluatists and multiplists were statistically significant individual predictors (see Table 5c). Notably, in all the models only the dummy variables comparing evaluativists with multiplists or 
with absolutists were statistically significant, while the variable comparing absolutists with multiplists was not statistically significant, providing further support to Hypothesis I. Adults ( $M$ $=4.118, S D=5.990$ ) showed greater usage of this particular type of epistemic statement than adolescents $(M=.463, S D=1.936)$. Also, evaluativists $(M=8.17, S D=10.110)$ used more high epistemic statements on evidence-claim relation than multiplitists $(M=0)$ and absolutists $(M=$ $1.573, S D=4.969)$.

When evaluativists served as the reference group for dummy variables, a multiple regression model for the science domain also was statistically significant $\left(R^{2}=.352, F(4,50)=\right.$ $6.776, p<.001)$. Age and epistemic perspective, particularly the dummy variable comparing multiplists versus evaluativists, were statistically significant individual predictors of the variance in usage of high epistemic statements on evidence-claim relation in the science domain. Evaluativists exhibited greater use of high epistemic statements $(M=5.860, S D=9.682)$ than multiplists $(M=0)$. Also, adults $(M=7.168, S D=9.685$ produced more high epistemic statements than young adolescents $(M=.932, S D=3.898)$. With absolutists as the reference group for dummy variables, the regression model was statistically significant $\left(R^{2}=.352, F(4,50)\right.$ $=6.776, p<.001$ ) and age was a statistically significant predictor (see Table 5b). With multiplists as the reference group for dummy variables, the regression model was statistically significant $\left(R^{2}=.352, F(4,50)=6.776, p<.001\right)$. Age and the dummy variable comparing multipists versus evaluativists were statistically significant predictors (see Table 5c).

\subsection{Epistemic Perspective and Prior Knowledge as Possible Mediators between Age and}

\section{Epistemic Processing}


To gain a better understanding of the relation between age, epistemic perspective (EP), prior knowledge $(\mathrm{PK})$ and epistemic processing, we examined whether epistemic perspective and prior knowledge mediated relations between age and epistemic processing. To test the mediation models depicted in Figures 1-4, we used Hayes and Preacher's (2014) PROCESS SPSS macro, which is recommended for mediational models with small numbers as it maintains higher levels of power while controlling for Type I errors (Preacher \& Hayes, 2008). Moreover, given that the bootstrapping technique expects effects to be non-normal, PROCESS was suitable for our data because it is based on a non-parametric distribution (Hayes \& Preacher, 2014). We used unstandardized values for PROCESS, following Hayes’ (2013) recommendation, but standardized values are reported in figures for ease of interpretation.

\subsubsection{High online epistemic statements on credibility.}

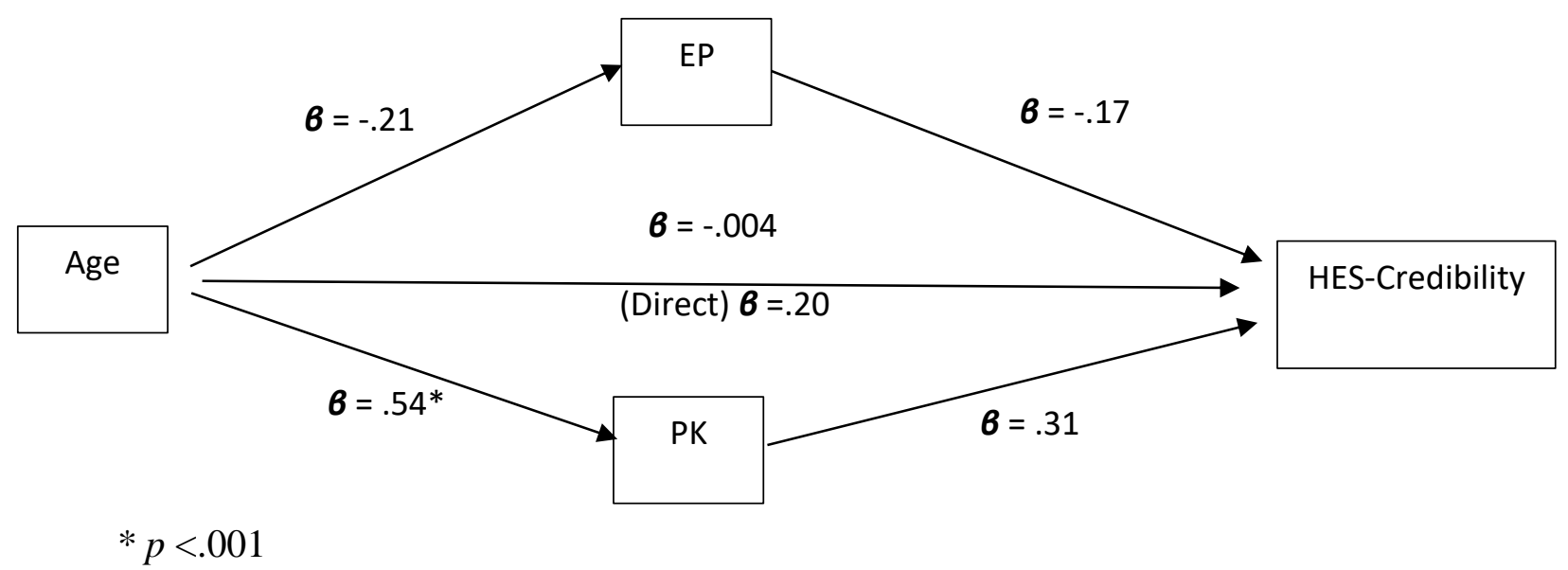

Figure 1. Mediation relations between Age, Epistemic Perspective (EP), Prior Knowledge (PK) and High Epistemic Statements (HES) on Credibility in the History Domain. Values shown in the figure are standardized for ease of interpretation.

Path analysis was used to investigate the hypothesis that EP and PK mediate the effect of age on production of high epistemic statements (HES) on credibility in the social domain. The total 
effects model was not significant, $t=1.02, p=.31$. For specific direct effects, results indicated that age was not a significant predictor of EP, $b=-.19, S E=.14, p=.17$, and EP was not a significant predictor of usage of HES on credibility, either, $b=-1.25, S E=1.12, p=.27$. Age was a significant predictor of PK, $b=.40, S E=.09, p<.001$, but PK was not a significant predictor of HES on credibility, $b=2.79, S E=1.53, p=.07$. The path coefficient for age changed from $b=1.32, S E=1.30, p=.31$, before the inclusion of the mediators, to $b=-.02, S E=1.06, p$ $=.98$, after the inclusion of the meditators. The indirect effect was tested using a bootstrap estimation approach with 10000 samples (Shrout \& Bolger, 2002). Results indicated that EP was not a significant mediator between age and credibility, $\mathrm{CI}=-.0586-1.3746$, whereas $\mathrm{PK}$ was a significant mediator, $\mathrm{CI}=.3581-2.7422($ Zhao, Lynch, \& Chen, 2010).

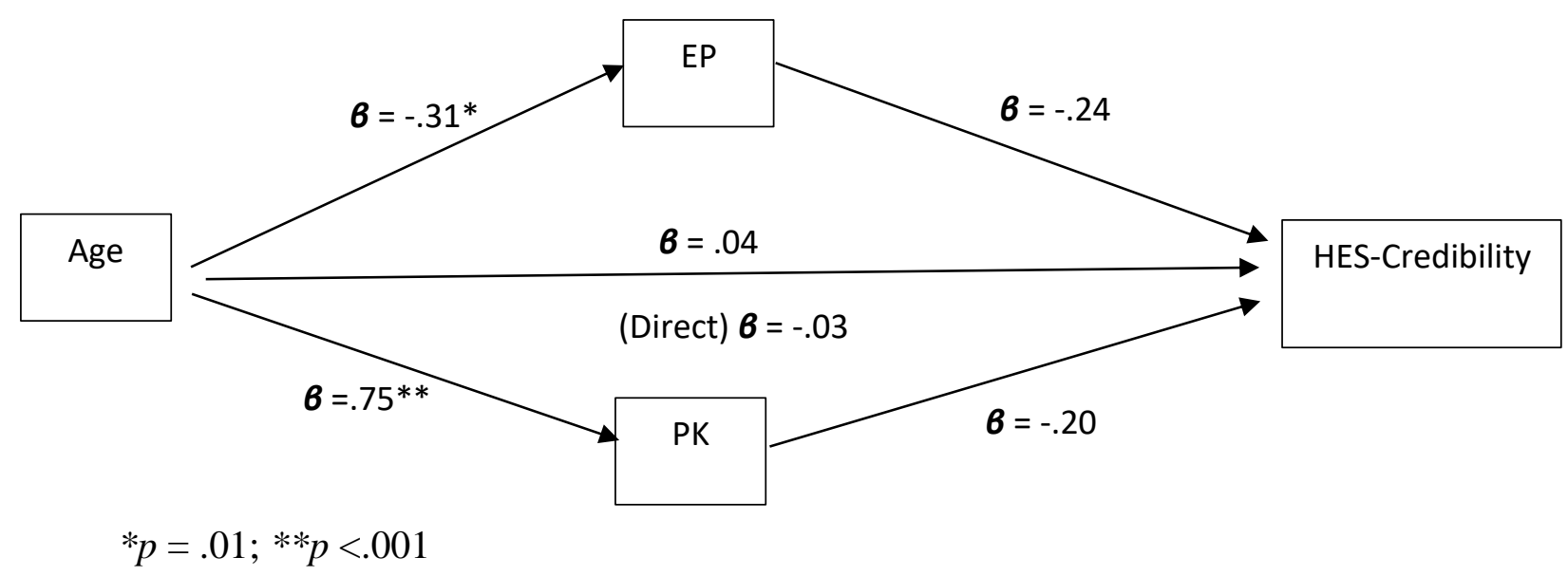

Figure 2. Mediation relations between Age, Epistemic Perspective (EP), Prior Knowledge (PK) and High Epistemic Statements on Credibility in the Science Domain, with standardized values. 
For the science domain, the total effects model was not significant, $t=-.25, p=.80$. Results indicated that age was a significant predictor of $\mathrm{EP}, b=-.25, S E=.10, p=.01$, but EP was not a significant predictor of HES on credibility, $b=-0.11, S E=.01, p=.25$. Age was a significant predictor of PK, $b=.60, S E=.08, p<.001$, but PK was not a significant predictor of HES on credibility, $b=-.01, S E=.01, p=.22$. The path coefficient for age changed from before to after inclusion of the mediators in the model from $b=-.001, S E=.004, p=.80$ to $b=.001, S E=.005$, $p=.73$. Using a bootstrap bias-corrected estimation approach, results indicated that both EP (CI $=.0004-.0101)$ and PK (CI = -.0159- -.0011) were significant mediators between age and HES on credibility. The finding that despite no statistical significance for the direct path from age to outcomes, or from a mediator to an outcome, the test of mediation was statistically significant may seem surprising. Traditionally, researchers have relied on Baron and Kenny's (1986) criteria for establishing mediation. However, Zhao, Lynch, and Chen (2010) have published an article that demonstrate how both direct effects need not be significant, but an indirect effect can be. "Second, there need not be a significant 'effect to be mediated' in equation 2 . There should be only one requirement to establish mediation, that the indirect effect $a \times b$ be significant." (p. 198). In other words, path a, the direct effect between $X$ and $M$, need not be significant, nor does the path from $M$ to $Y$ (path b). This is based on the idea that indirect effects are an interaction between two paths, which can magnify an effect.

\subsubsection{High epistemic statements on evidence-claim relation.}




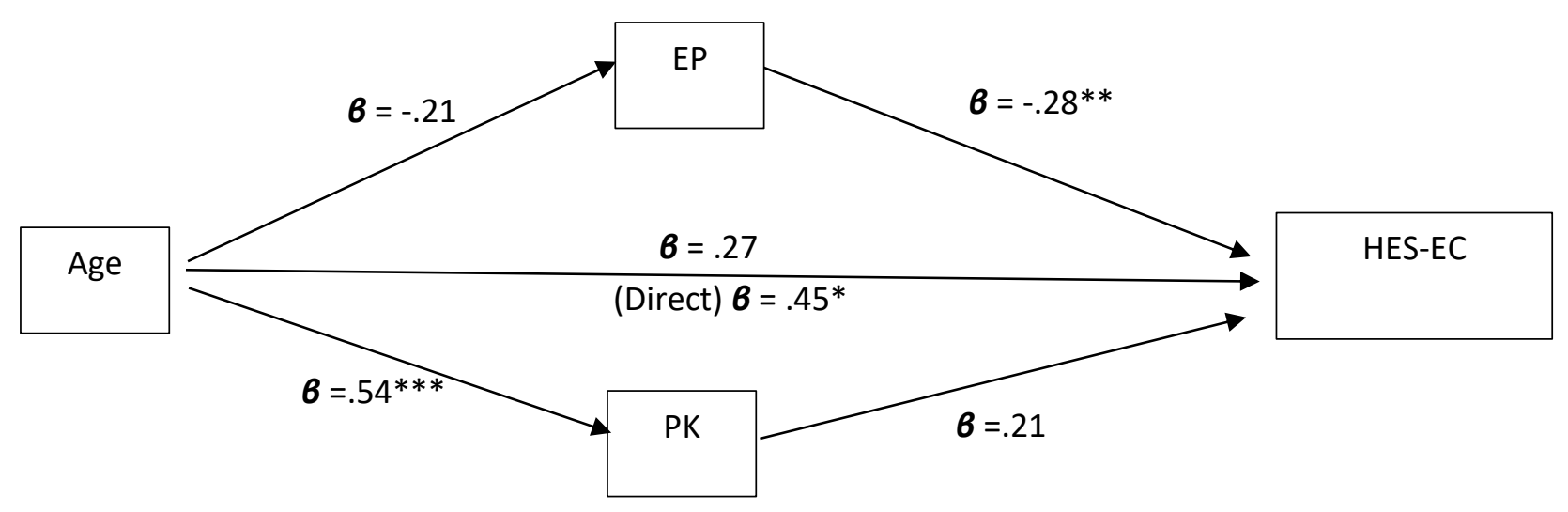

$* p=.02 ; * * p=.05 ; * * * p<.001$

Figure 3. Mediation relations between Age, Epistemic Perspective (EP), Prior Knowledge (PK) and High Epistemic Statements (HES) on Evidence-Claim relation in the History Domain, with standardized values.

For the history domain, the total effects model was significant, $t=2.47, p=.02$. Results indicated that age was not a significant predictor of EP, $b=-.19, S E=.14, p=.17$, and EP was a significant predictor of HES on evidence-claim relation, $b=-1.33, S E=.67, p=.05$. Age was a significant predictor of $\mathrm{PK}, b=.40, S E=.10, p<.001$, but PK was not a significant predictor of HES on evidence-claim relation, $b=1.26, S E=.85, p=.14$. The path coefficient for age changed from before to after inclusion of the mediators in the model from $b=1.94, S E=.79, p=$ .02 to $b=1.19, S E=.68, p=.09$. No significant mediations were found for EP CI $=-.0357-$ .9971 , or PK, CI $=-.0918-1.2828$.

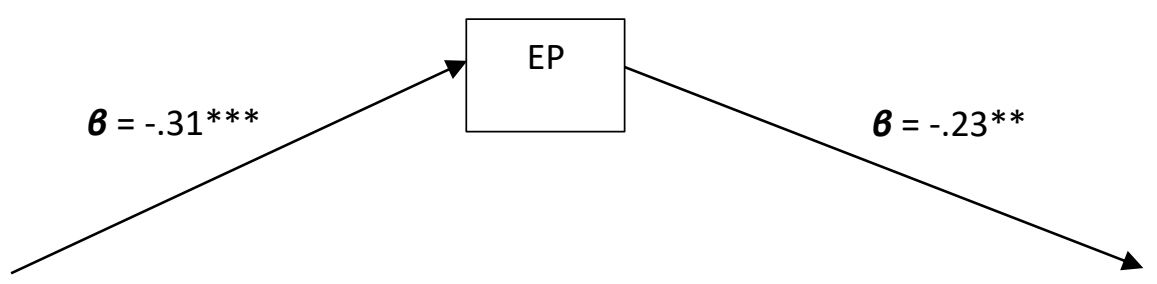




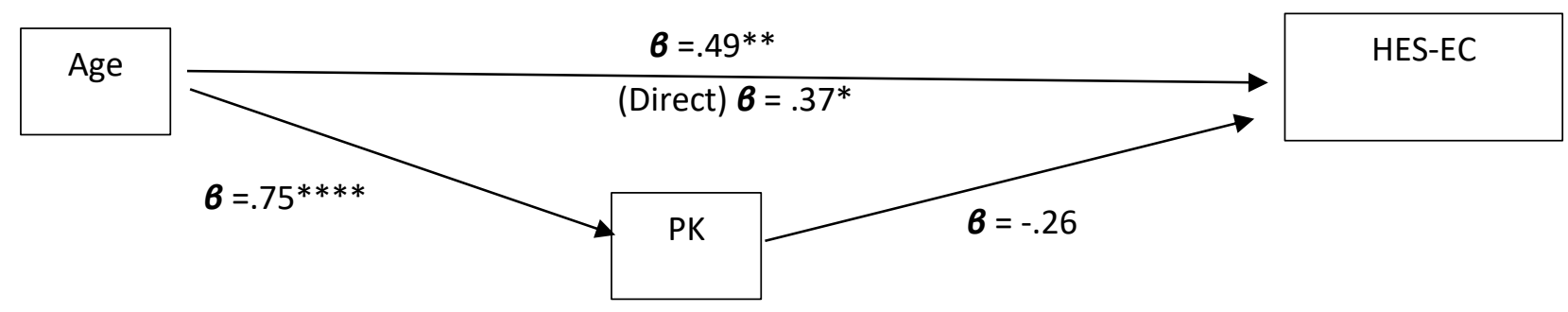

$* p=.03 ; * * p=.04 ; * * * p=.01 ; * * * * p<.001$

Figure 4. Mediation relations between Age, Epistemic Perspective (EP), Prior Knowledge (PK) and High Epistemic Statements on Evidence-Claim relation in the Science Domain, with standardized values.

For the science domain, the total effects model was significant, $t=2.18, p=.03$. Results indicated that age was a significant predictor of $\mathrm{EP}, b=.25, S E=.10, p=.01$, and that $\mathrm{EP}$ was a significant predictor of HES on evidence-claim relation, $b=-1.87, S E=.86, p=.04$. Age was also a significant predictor of $\mathrm{PK}, b=.60, S E=.08, p<.001$, but $\mathrm{PK}$ was not a significant predictor of usage of HES on evidence-claim relation, $b=-2.13, S E=1.35, p=.12$. The path coefficient for age changed from before to after inclusion of the mediators in the model from $b=$ 2.37, $S E=1.09, p=.03$ to $b=3.17, S E=1.54, p=.04$. For mediation, results indicated the indirect effect was significant when EP was the mediator, $\mathrm{CI}=.1067-1.4415$ and when PK was the mediator, $\mathrm{CI}=-3.5353--.1022$. These results support Hypothesis 3 that EP mediates the relationship between age and epistemic processing.

\subsection{Domain Differences in Online Epistemic Processing}

Comparing participants' epistemic perspective between the history and science domains to address research question 2, notable differences were observed. In particular, the number of participants who exhibited an evaluativist epistemic perspective in the science domain (22 out of 61) was greater than the number of participants who exhibited an evaluativist perspective in the 
history domain $(17$ out of 58$), X^{2}(1, N=58)=39.353, p<.001$. Although the number of participants who exhibited a multiplist epistemic perspective was small in both domains, more participants were multiplists in the science domain (10 out of 61$)$ than in the history domain (6 out of 58). $X^{2}(1, N=58)=32.123, p<.001$. Finally, the number of participants who exhibited an absolutist epistemic perspective was greater in the history domain (35 out of 58) than in the science domain $(29$ out of 61$), X^{2}(1, N=58)=38.114, p<.001$.

Paired samples t-test showed that participants had higher prior knowledge in the history topic $(M=.98, S D=.73)$ than in the science topic $(M=.71, S D=.80), t(51)=3.083, p=.003$.

3.3.1. High online epistemic statements on credibility. A Wilcoxon Signed-ranks test was used to compare participants' frequencies of high epistemic processing of evidence, regarding credibility of evidence, between the science and history domains. The Wilcoxon Signed-ranks test was used because the frequencies of high epistemic processing were not normally distributed. Results showed that participants engaged in more high epistemic processing of evidence in the history domain $(M=1.91, S D=6.589)$ than in the science domain $(M=.0074, S D=.036)(Z=-2.105, p=.035)$, confirming Hypothesis 4.

3.3.2. Low online epistemic statements on credibility. A Wilcoxon Signed-ranks test comparing participants' frequencies of low epistemic processing of evidence, regarding credibility of evidence, between the science and history domains showed that participants engaged also in more low epistemic processing of evidence in the history domain $(M=1.47, S D$ $=2.113)$ than in the science domain $(M=.29, S D=.838)(Z=4.243, p<.001)$.

\subsubsection{High epistemic statements on evidence-claim relation. No significant} differences were observed between participants' high epistemic processing of evidence regarding 
the evidence-claim relation between the history and science domains $(M=1.788, S D=4.285 ; M$ $=2.113, S D=6.392$, respectively).

\section{Discussion}

The purpose in the present study was to examine whether participants with different epistemic perspective process evidence differently during moment-by-moment reading of texts. We also examined whether there were any age or domain differences in online epistemic processing of evidence. Our findings suggested that individuals with evaluativist epistemic perspective and high levels of prior knowledge produced more high level epistemic judgments regarding the credibility and function of evidence in the context of an argument than did multiplists or absolutists. These findings are consistent with Muis's (2007) and Kuhn's (2001) theoretical frameworks and provide support for Hypothesis 1. Also, adults engaged in high epistemic processing of evidence more than young adolescents, supporting Hypothesis 2. When examined if epistemic perspective and prior knowledge had any mediation effects on the relation between age and epistemic processing, results only partially confirmed Hypothesis 3 , showing that epistemic perspective and prior knowledge mediated age and epistemic processing in the science domain. These results showed the importance of epistemic perspective above and beyond age for epistemic processing. Finally, participants engaged in high epistemic processing of evidence in the history domain more than in the science domain, supporting Hypothesis 4 . We discuss each of these results in more depth next.

\subsection{Epistemic Perspective and Online Epistemic Processing}

The findings of the present study add to the growing body of evidence showing that evaluativist epistemic perspective supports engagement in reflective thinking (Kendeou, Muis, \& Fulton, 2011; Mason et al., 2010; Muis \& Franco, 2010; Strøms $\varnothing$ \& Bråten, 2010). Specifically, 
the focus on the online epistemic processing of evidence employed shows that examining how individuals process evidence when reading a text can directly inform our understanding of how epistemic perspective relates to epistemic processing. Individuals with an evaluativist epistemic perspective tend to engage in high online epistemic processing more, reflecting on the evidence's credibility and its function in providing support to its associated claim in the context of an argument. Therefore, our findings suggest that one's epistemic perspective guides one's type of processing (epistemic or non-epistemic), as well as level of processing (superficial versus highlevel) when reading a text. The findings are also consistent with Stømsø and colleague’s (2011) results showing that individuals who endorsed justification for knowing based on criteria and evidence were more likely to pay attention to text content when asked to evaluate a text, than individuals who relied on personal eyewitness experiences as the criterion for judging a text. The present study extends the existing literature by demonstrating that epistemic perspective not only influences comprehension of multiple texts (Bråten et al., 2011), but also processing of evidence in the context of a single text.

The findings of the present study also add to current theoretical accounts that explain the relation between epistemic perspective and epistemic processing. Recall that Muis (2007) proposed that individuals' beliefs translate into standards for learning as well as epistemic standards that serve as inputs to epistemic processing. For example, individuals who espoused absolutist beliefs (which she called less constructivist) may set comprehension standards ("Do I know this?") that are met once a memorization of information is accomplished. From an epistemic processing standpoint, this results in a shallow or low-level assessment of whether learning has occurred. When epistemic cognition is translated into epistemic standards (e.g., “How do I know this?" and "Do I believe this?"), individuals with an absolutist stance readily 
accept information presented to them when experts or authority figures provide that information (e.g., "It should be true, if the scientists said so"). In contrast, individuals who espouse more evaluativist beliefs set comprehension standards that go beyond a mere repetition of information, and critically evaluate that information for its veracity. Sources of that information are also critically evaluated and evidence compared (e.g., "This evidence is not proof'), as the results of the present study showed.

Recall that Kuhn (2001) proposed that individuals with evaluativist epistemic perspective view alternative positions of an issue as judgments that can be compared and evaluated according to the criteria of argument and evidence. Previous research showed that individuals with different epistemic perspective used evidence differently when asked to support their position (Kuhn, 1991). The present study adds to the existing literature by demonstrating that individuals with different epistemic perspective not only use evidence differently when they develop arguments (Mason \& Scirica, 2006), but they also process evidence differently when they encounter such evidence in a text. Thus, our findings contribute to our understanding of how epistemic perspective influences online epistemic processing of text. In particular, our findings showed that only individuals with evaluativist epistemic perspective are likely to engage in high online epistemic processing of evidence, evaluating evidence's credibility and function in the context of an argument.

Our finding that a high level of topic knowledge was associated with engagement in online epistemic processing is in line with prior work showing that a high level of prior knowledge is related to multiple-text comprehension (Ferguson \& Bråten, 2013).

\subsubsection{Age differences}


We believe that the age differences observed between epistemic perspective and online epistemic processing deserve careful consideration. Our findings of age-related developmental differences in engagement in online epistemic processing are consistent with the findings of other studies examining self-regulation more generally, which showed that older children and expert adults engaged in more self-monitoring than young children (Kitsantas \& Zimmerman, 2002; Roderer \& Roebers, 2014; van der Stel \& Veenman, 2010). These findings also highlight the importance of using a developmental approach in studying how epistemic perspective affects thinking.

Notably, only half of the adult participants held evaluativist views regarding the nature of knowledge and knowing and those who held evaluativist views engaged in limited online epistemic processing of evidence. This finding is consistent with other studies showing that adults engage in low levels of reflective thinking (Birch \& Bloom, 2007; Zhang et al., 2010) and suggests that maturity alone does not support engagement in high epistemic processing. Thus, further research is required to examine what supports development of high level epistemic processing.

\subsection{Domain Differences}

The differences observed in epistemic perspective across the two domains examined in the present study are consistent with previous work (Iordanou, 2010; Kuhn, et al., 2000; Kuhn, Iordanou, et al., 2008; Muis, et al., 2016; Strømsø, et al., 2011), offering further support to the view that epistemic cognition is domain-specific. Of particular interest are the differences observed in participants' online epistemic processing of evidence. Participants overall engaged in online epistemic processing of evidence more in the history topic than in the science topic. This finding could be due to the fact that participants had better prior knowledge of the history topic 
than of the science topic, as indicated by the prior knowledge tests. This could be a possible explanation, especially considering our adult sample. The adult sample in this study consisted of first year graduate students who were pursuing a master's degree in Educational Psychology. Most of the students held an undergraduate degree in Education or Classics, but none of them had a degree in the Sciences.

Another possible explanation for the domain differences in online epistemic processing of evidence that we observed could be differences in epistemic evidential standards across domains (Chinn et al., 2011; Iordanou, 2016a). In Iordanou's (2016a) study, when young adolescents were asked through a personal interview to report their views about their own and scientists' process of knowing in the social and science domains, they reported that scientists pursue research and find evidence while they study the evidence that scientists produce in the science domain. In the social domain, the majority of young adolescents in that study reported that the way they know about the topic and the way scientists do is the same, identifying personal experience and subjective thinking as the main means for knowing. Therefore, the domain differences observed in online epistemic processing of evidence in the present study could be due to differences in individuals' epistemic cognition of evidence across domains. Specifically, individuals might view evidence as amenable to interpretation more so in history than in the science domain. Further research, using more sensitive instruments assessing particularly students' epistemic cognition of evidence and evidential standards across different domains, is needed to investigate this possibility.

\subsection{Educational Implications and Future Research}

The present findings, as well as others (Muis et al., 2011), showed that individuals generally exhibited little engagement in epistemic thinking about the justification employed in a 
text to support a position. We believe this is concerning, considering the important role of critical evaluation in the $21^{\text {st }}$ century (NGSS Lead States, 2013). Yet, for those individuals who engaged in epistemic processing, the determining factors were an evaluativist epistemic perspective along with high topic knowledge. This finding has important educational implications. Justification of one's own knowledge, which is central in epistemic perspective (Bråten et al., 2011; Greene, Muis, \& Pieschl, 2010), guides how we process evidence when reading a text. Thus, investing in developing students' epistemic perspective, through interventions such as Muis and Duffy's (2013) constructivist teaching practices, and Iordanou and Constantinou's (2015) argumentation practices, appears to be a promising pathway for supporting students to develop their reflective thinking during reading. We recommend that future research examine the effect of interventions that aim to support the development of epistemic perspective on students' online epistemic processing when reading a text.

Furthermore, more work is required to understand better the relation between epistemic perspective and epistemic processing. Further research is required that includes a more diverse sample. In addition, the possible effect of the evidence's representation format (Muis et al, 2011), individuals' characteristics such as epistemic aims and values (Chinn, et al., 2011), as well as the role of affect when conflicting texts are used needs to be examined (see Muis, Pekrun, Sinatra, Azevedo, Trevors, Meier \& Heddy, 2015). There is also a need to find more sensitive measures for accessing epistemic processing. In the present work, and even though think-alouds revealed participants' epistemic processing, the frequency of those processes was low. This, may be due, in part, to the methodology itself, as think-alouds only reveal a subset of processes that individuals are aware of; individuals, however, also engage in processes they are not aware of. 
Nevertheless, the present work examining epistemic perspectives and epistemic processing, is a first attempt in bridging the more traditional frameworks of epistemology with the recent call for studying epistemic activity in action (Iordanou, 2016b) and situated epistemic cognition (Clark et al., 2011). Studying online epistemic processing can provide enlightening insights on individuals' epistemic ideals and reliable processes of knowing, that is the standards people employ for knowing and what they perceive as reliable means to know respectively (Chinn \& Rinehart, 2016), and even more importantly it can be a promising way to study how individuals' epistemic standards change (Iordanou, 2016b). Developing critical thinkers is probably one of the most important but also most challenging objectives in education (NGSS Lead States, 2013). Thus, gaining a deeper understanding of the development of critical evaluation during reading is, we believe, a worthwhile research endeavor. 


\section{References}

Bannert, M., \& Mengelkamp, C. (2008). Assessment of metacognitive skills by means of instruction to think aloud and reflect when prompted. Does the verbalisation method affect learning?. Metacognition and Learning, 3(1), 39-58.

Baron, R. M., \& Kenny, D. A. (1986). The moderator-mediator variable distinction in social psychological research: Conceptual, strategic, and statistical considerations. Journal of Personality and Social Psychology, 51(6), 1173.

Barzilai, S., \& Weinstock, M. (2015). Measuring epistemic thinking within and across topics: A scenario-based approach. Contemporary Educational Psychology, 42, 141-158.

Barzilai, S., \& Zohar, A. (2014). Reconsidering personal epistemology as metacognition: A multifaceted approach to the analysis of epistemic thinking. Educational Psychologist, 49(1), 13-35.

Barzilai, S., \& Zohar, A. (2016). Epistemic (meta)cognition: Ways of thinking about knowledge and knowing. In J. A. Greene, W. A. Sandoval, \& I. Bråten (Eds.). Handbook of epistemic cognition. New York, NY: Routledge.

Birch, S. A. J., \& Bloom, P. (2007). The curse of knowledge in reasoning about false beliefs. Psychological Science, 18(5), 382-386.

Braasch, J.L.G., Bråten, I., Britt, M.A., Steffens, B., \& Strømsø, H.I. (2014). Sensitivity to inaccurate argumentation in health news articles: Potential contributions of readers' topic and epistemic beliefs. In D.N. Rapp \&, J.L.G. Braasch (Eds), Processing inaccurate information: theoretical and applied perspectives from cognitive science and the educational sciences. MIT Press. 
Bråten, I., Britt, M. A., Strømsø, H. I., \& Rouet, J. F. (2011). The role of epistemic beliefs in the comprehension of multiple expository texts: Toward an integrated model. Educational Psychologist, 46(1), 48-70.

Bråten, I., Strømsø, H. I., \& Salmerón, L. (2011). Trust and mistrust when students read multiple information sources about climate change. Learning and Instruction, 21(2), 180-192.

Britt, M.A., Richter, T., \& Rouet, J. (2014). Scientific literacy: The Role of goal-directed reading and evaluation in understanding scientific information. Educational Psychologist, 49(2), 104-122.

Bromme, R., Pieschl, S., \& Stahl, E. (2010). Epistemological beliefs are standards for adaptive learning: A functional theory about epistemological beliefs and metacognition. Metacognition and Learning, 5(1), 7-26.

Butler, D. L., \& Winne, P. H. (1995). Feedback and self-regulated learning: A theoretical synthesis. Review of Educational Research, 65(3), 245-281.

Chinn, C. A., Buckland, L. A., \& Samarapungavan, A. (2011). Expanding the dimensions of epistemic cognition: Arguments from philosophy and psychology. Educational Psychologist, 46(3), 141-167.

Chinn, C. A., \& Rinehart, R. W. (2016). Epistemic cognition and philosophy: Developing a new framework for epistemic cognition. In J. A. Greene, W. A. Sandoval, \& I. Bråten (Eds.). Handbook of epistemic cognition (pp. 835-866). New York: Routledge.

Ferguson, L. E., \& Bråten, I. (2013). Student profiles of knowledge and epistemic beliefs: Changes and relations to multiple-text comprehension. Learning and Instruction, 25, 4961. 
Flavell, J. H., Miller, P. H., \& Miller, S. A. (2002). Cognitive development (4th ed.). Upper Saddle River, NJ: Prentice Hall.

Greene, J. A., Azevedo, R., Torney-Purta, J. (2008). Modelling epistemic and ontological cognition: Philosophical perspectives and methodological directions. Educational Psychologist, 43(3), 142-160.

Greene, J. A., Muis, K. R., \& Pieschl, S. (2010). The role of epistemic beliefs in students' selfregulated learning with computer-based learning environments: Conceptual and methodological issues. Educational Psychologist, 45(4), 245-257.

Greene, J. A., Sandoval, W. A., \& Bråten, I. (2016). An introduction to epistemic cognition. In J. A. Greene, W. A. Sandoval, \& I. Bråten (Eds.). Handbook of epistemic cognition. New York, NY: Routledge.

Greene, J. A., Yu, S. B., \& Copeland, D. Z. (2014). Measuring critical components of digital literacy and their relationships with learning. Computers \& Education, 76, 55-69.

Hayes, A. F. (2013). Introduction to mediation, moderation, and conditional process analysis: A regression-based approach. Guilford Publications.

Hayes, A. F., \& Preacher, K. J. (2014). Statistical mediation analysis with a multicategorical independent variable. British Journal of Mathematical and Statistical Psychology, 67(3), $451-470$.

Hofer, B. K. (2004). Epistemological understanding as a metacognitive process: Thinking aloud during online searching. Educational Psychologist, 39(1), 43-55.

Hofer, B. K., \& Pintrich, P. R. (1997). The development of epistemological theories: Beliefs about knowledge and knowing and their relation to learning. Review of Educational Research, 67(1), 88-140. 
Hofer, B. K., \& Sinatra, G. M. (2010). Epistemology, metacognition, and self-regulation: Musings on an emerging field. Metacognition and Learning, 5(1), 113-120.

Howitt, D., \& Cramer, D. (2014). An introduction to statistics in psychology. UK: Pearson.

Iordanou, K. (2010). Developing argument skills across scientific and social domains. Journal of Cognition and Development, 11(3), 293-327.

Iordanou, K. (2016a). Developing epistemological understanding through argumentation in scientific and social domains. Special issue on learning through argumentation. Zeitschrift für Pädagogische Psychologie, 30(2-3), 109-119.

Iordanou, K. (2016b). From theory of mind to epistemic cognition. A Lifespan perspective. Frontline Learning Research, 4(5), 106 - 119.

Iordanou, K., \& Constantinou, C. P. (2014). Developing pre-service teachers' evidence-based argumentation skills on socio-scientific issues. Learning and Instruction, 34, 42-57.

Iordanou, K., \& Constantinou, C. P. (2015). Supporting use of evidence in argumentation through practice in argumentation and reflection in the context of SOCRATES learning environment. Science Education, 99(2), 282-311.

Iordanou, K., Kendeou, P., \& Beker, K. (2016). Argumentative reasoning. In J. A. Greene, W. A. Sandoval, \& I. Bråten (Eds.). Handbook of epistemic cognition. (pp. 67-98). New York, NY: Routledge.

Kendeou, P., Muis, K. R., \& Fulton, S. (2011). Reader and text factors in reading comprehension processes. Journal of Research in Reading, 34(4), 365-383.

King, P. M. \& Kitchener, K. S. (1994). Developing reflective judgment: Understanding and promoting intellectual growth and critical thinking in adolescents and adults. San Francisco: Jossey-Bass. 
Kitsantas, A., \& Zimmerman, B. J. (2002). Comparing self-regulatory processes among novice, non-expert, and expert volleyball players: A microanalytic study. Journal of Applied Sport Psychology, 14(2), 91-105.

Kuhn, D. (1991). The skills of argument. Cambridge, UK: Cambridge University Press.

Kuhn, D. (2001). How do people know? Psychological Science, 12(1), 1-8.

Kuhn, D., Cheney, R., \& Weinstock, M. (2000). The development of epistemological understanding. Cognitive Development, 15(3), 309-328.

Kuhn, D., Goh, W., Iordanou, K., \& Shaenfield, D. (2008). Arguing on the computer: A microgenetic study of developing argument skills in a computer-supported environment. Child Development, 79(5), 1310-1328.

Kuhn, D., Iordanou, K., Pease, M., \& Wirkala, C. (2008). Beyond control of variables: What needs to develop to achieve skilled scientific thinking? Cognitive Development, 23(4), $435-451$.

Lin, Y. C., Liang, J. C., \& Tsai, C. C. (2012). The relationships between epistemic beliefs in biology and approaches to learning biology among biology-major university students in Taiwan. Journal of Science Education and Technology, 21(6), 796-807.

Mason, L., Ariasi, N., \& Boldrin, A. (2011). Epistemic beliefs in action: Spontaneous reflections about knowledge and knowing during online information searching and their influence on learning. Learning and Instruction, 21(1), 137-151.

Mason, L., Boldrin, A., \& Ariasi, N. (2010). Epistemic metacognition in context: Evaluating and learning online information. Metacognition and Learning, 5(1), 67-90.

Mason, L., \& Scirica, F. (2006). Prediction of students' argumentation skills about controversial topics by epistemological understanding. Learning and Instruction, 16(5), 492-509. 
Meijer, J., Veenman, M. V. J., \& Van Hout-Wolters, B. H. A. M. (2006). Metacognitive activities in text studying and problem solving: development of a taxonomy. Educational Research and Evaluation, 12(3), 209-238.

Mills, C. M. (2013). Knowing when to doubt: developing a critical stance when learning from others. Developmental Psychology, 49(3), 404-418.

Muis, K. R. (2007). The role of epistemic beliefs in self-regulated learning. Educational Psychologist, 42(3), 173-190.

Muis, K. R. (2008). Epistemic profiles and self-regulated learning: Examining relations in the context of mathematics problem solving. Contemporary Educational Psychology, 33(2), 177-208.

Muis, K. R., Bendixen, L. D., \& Haerle, F. (2006). Domain -generality and domain-specificity in personal epistemology research: Philosophical and empirical reflections in the development of a theoretical framework. Educational Psychology Review, 18(1), 3-54.

Muis, K. R., \& Duffy, M. C. (2013). Epistemic climate and epistemic change: Instruction designed to change students' beliefs and learning strategies and improve achievement. Journal of Educational Psychology, 105(1), 213-225.

Muis, K. R., \& Franco, G. M. (2010). Epistemic profiles and metacognition: Support for the consistency hypothesis. Metacognition and Learning, 5(1), 27-45.

Muis, K. R., Franco, G. M., \& Gierus, B. (2011). Examining epistemic beliefs across conceptual and procedural knowledge in statistics. International Journal on Mathematics Education, 43(4), 507-519. 
Muis, K. R., Kendeou, P., \& Franco, G. M. (2011). Consistent results with the consistency hypothesis? The effects of epistemic beliefs on metacognitive processing. Metacognition and Learning, 6(1), 45-63.

Muis, K. R., Pekrun, R., Sinatra, G. M., Azevedo, R., Trevors, G., Meier, E., \& Heddy, B. C. (2015). The curious case of climate change: Testing a theoretical model of epistemic beliefs, epistemic emotions, and complex learning. Learning and Instruction, 39, 168-183.

Muis, K. R., Trevors, G., Duffy, M., Ranellucci, J., \& Foy, M. J. (2016). Testing the TIDE: Examining the nature of students' epistemic beliefs using a multiple methods approach. The Journal of Experimental Education, 84(2), 264-288.

NGSS Lead States. (2013). Next generation science standards: For states, by states. Washington, DC: The National Academies Press.

Preacher, K. J., \& Hayes, A. F. (2008). Asymptotic and resampling strategies for assessing and comparing indirect effects in multiple mediator models. Behavior Research Methods, 40(3), 879-891.

Puustinen, M., \& Pulkkinen, L. (2001). Models of self-regulated learning: A review. Scandinavian Journal of Educational Research, 45(3), 269-286.

Roderer, T., \& Roebers, C. M. (2014). Can you see me thinking (about my answers)? Using eyetracking to illuminate developmental differences in monitoring and control skills and their relation to performance. Metacognition and Learning, 9(1), 1-23.

Sandoval, W. A., \& Millwood, K. A. (2005). The quality of students' use of evidence in written scientific explanations. Cognition and Instruction, 23(1), 23-55.

Schommer, M. (1994). Synthesizing epistemological belief research: Tentative understandings and provocative confusions. Educational Psychology Review, 6(4), 293-319. 
Shrout, P. E., \& Bolger, N. (2002). Mediation in experimental and nonexperimental studies: New procedures and recommendations. Psychological Methods, 7(4), 422-445.

Sinatra, G. M., Kienhues, D., \& Hofer, B. K. (2014). Addressing challenges to public understanding of science: Epistemic cognition, motivated reasoning, and conceptual change. Educational Psychologist, 49(2), 123-138.

Stahl, E., Pieschl, S., \& Bromme, R. (2006). Task complexity, epistemological beliefs and metacognitive calibration: An exploratory study. Journal of Educational Computing Research, 35(4), 319-338.

Strøms $\varnothing$, H. I., \& Bråten, I. (2010). The role of personal epistemology in the self-regulation of internet-based learning. Metacognition and Learning, 5(1), 91-111.

Strømsø, H. I., Bråten, I., \& Britt, M. A. (2011). Do students’ beliefs about knowledge and knowing predict their judgement of texts' trustworthiness? Educational Psychology, 31(2), 177-206.

Tabachnick, B. G., \& Fidell, L. S. (1996). Using multivariate statistics (3rd ed.). New York: HarperCollins.

van der Stel, M., \& Veenman, M. V. (2010). Development of metacognitive skillfulness: A longitudinal study. Learning and Individual Differences, 20(3), 220-224.

van der Stel, M., \& Veenman, M. V. (2014). Metacognitive skills and intellectual ability of young adolescents: A longitudinal study from a developmental perspective. European Journal of Psychology of Education, 29(1), 117-137.

Veenman, M. V. J. (2011). Alternative assessment of strategy use with self-report instruments: a discussion. Metacognition and Learning, 6(2), 205-211. 
Veenman, M. V., Wilhelm, P., \& Beishuizen, J. J. (2004). The relation between intellectual and metacognitive skills from a developmental perspective. Learning and Instruction, 14(1), 89-109.

Walton, D. N. (1989). Dialogue theory for critical thinking. Argumentation, 3, 169-184.

Winne, P. H., Jamieson-Noel, D., \& Muis, K. (2002). Methodological issues and advances in researching tactics, strategies, and self-regulated learning. Advances in motivation and achievement: New directions in measures and methods, 12, 121-155.

Zhang, T., Zheng, X., Zhang, L., Sha, W., Deák, G., \& Li, H. (2010). Older children’s misunderstanding of uncertain belief after passing the false belief test. Cognitive Development, 25(2), 158-165.

Zhao, X., Lynch, J. G., \& Chen, Q. (2010). Reconsidering Baron and Kenny: Myths and truths about mediation analysis. Journal of Consumer Research, 37(2), 197-206. 
Table 1

Participants' Epistemic Perspective by Age and Domain

\begin{tabular}{lcccccc}
\hline & \multicolumn{5}{c}{ History Domain } & \multicolumn{2}{c}{ Science Domain } \\
\cline { 2 - 7 } & Absolutists & Multiplists & Evaluativists & Absolutists & Multiplists & Evaluativists \\
\hline $\begin{array}{l}\text { Middle \& } \\
\text { Sigh }\end{array}$ & $57 \%$ & $15 \%$ & $28 \%$ & $43 \%$ & $24 \%$ & $33 \%$ \\
$\begin{array}{l}\text { Students } \\
\text { University } \\
\text { Graduate } \\
\text { Students }\end{array}$ & $(N=20)$ & $(N=5)$ & $(N=10)$ & $(N=16)$ & $(N=9)$ & $(N=12)$ \\
& $67 \%$ & $4 \%$ & $29 \%$ & $54 \%$ & $4 \%$ & $42 \%$ \\
\hline
\end{tabular}


Table 2

Types of Statements after Reading a piece of Evidence in the History and Science Texts.

\begin{tabular}{|c|c|c|c|}
\hline \multirow[t]{2}{*}{ Types } & \multirow[t]{2}{*}{ Example } & \multicolumn{2}{|c|}{$\begin{array}{c}\text { Overall } \\
\text { percent usage } \\
\text { (Standard Deviation) }\end{array}$} \\
\hline & & History Text & Science Text \\
\hline
\end{tabular}

A. Judging Evidence (focus on evidence itself)

Comments regarding:

I. Credibility of evidence, which is justified by

There are many

$2.27 \%(7.11) \quad 0.62 \%(3.57)$

a. The number of scientific studies.

studies supporting

this.

b. Methodology (Scientific

methodology).

We can trust scientific methodology.

II. Persuasiveness of evidence

Reference to whether evidence is convincing or not convincing, along with a justification.

III. Rightness of the evidence

Evaluation of the evidence in terms of right/wrong, along with a justification.

Based on research it

$0.0 \%(0)$ provides a convincing evidence.

This should be true;

$0.0 \%(0)$

$0.0 \%(0)$ carbon dioxide was released (in the atmosphere) which caused an increase in the temperate and the animals could not survive.

HIGH ONLINE EPISTEMIC PROCESSING OF EVIDENCE - CLAIM RELATION

B. Judging evidence-claim relation. (focus on evidence's role as back up for claims)

It provides us a convincing evidence
$1.88 \%(4.32)$

$2.35 \%(6.75)$ 
Comments regarding whether the evidence supports the claim that was supposed to support, the suitability of evidence in the context of argument and whether the evidence enhances claim's persuasiveness. here supporting that the explosion happened indeed.

\section{LOW ONLINE EPISTEMIC PROCESSING OF EVIDENCE- EMPLOYING EPISTEMIC STANDARDS OTHER THAN SCIENTIFIC RESEARCH OR NO STANDARDS}

A. Comments regarding

I. Credibility of evidence, which is justified by

a. Authority alone, without any attempt for evaluation.

b. Rule of majority. The majority of scientists support this.

c. First-hand Experience. It is an eyewitness account.

II. Persuasiveness of evidence

Reference to whether evidence is convincing or not convincing, with no justification.

\section{Rightness of the evidence}

Evaluation of the evidence in terms of right/wrong, with no justification.

B. General comments with no explanation.

C. Reference to personal knowledge
$1.77 \%(5.44)$

$.71 \%(3.86)$

It should be true, if the scientists said so.

Three researchers support that the lost island of Atlantis is in Santorini.

This sounds $.13 \%(1.03)$ $.62 \%(3.44)$ convincing.

This is right.

$5.22 \%(9.67) \quad 10.05 \%(20.46)$

This is interesting.

$7.20 \%(16.50) \quad 5.23 \%(12.14)$

I have read this somewhere, I know this

\section{NON-EPISTEMIC COGNITIVE PROCESSING}

I. Repeat the evidence

II. Ask for clarification regarding the evidence
Here it says about the

$59.17 \%$ (39.08) 68.76\% (35.45) habitats of the island and how the island got its name.

How cold was it? 
Table 3

Means and Standard Deviations of Prior Knowledge by Epistemic Cognition, Age and Topic.

\begin{tabular}{|c|c|c|c|c|c|}
\hline & \multicolumn{3}{|c|}{ Epistemic Cognition } & \multicolumn{2}{|c|}{ Age } \\
\hline & Absolutists & Multiplists & Evaluativists & Adolescents & Adults \\
\hline History & $.78(.80)$ & $1.00(.76)$ & $1.29(.47)$ & $.71(.63)$ & $1.50(.62)$ \\
\hline Topic & $(N=35)$ & $(N=6)$ & $(N=17)$ & $(N=35)$ & $(N=23)$ \\
\hline Science & $.20(.41)$ & $.90(.97)$ & $.85(.67)$ & $.28(.51)$ & $1.47(.61)$ \\
\hline Topic & $(N=29)$ & $(N=10)$ & $(N=22)$ & $(N=37)$ & $(N=24)$ \\
\hline
\end{tabular}


Table 4a

Summary of Multiple Regression Analysis on High Epistemic Processing on Credibility, using Epistemic Cognition, Prior Knowledge and Age as predictors, by Domain.

\begin{tabular}{|c|c|c|c|c|c|c|c|c|}
\hline \multirow[b]{2}{*}{ Variable } & \multicolumn{4}{|c|}{ History Domain } & \multicolumn{4}{|c|}{ Science Domain } \\
\hline & $B$ & $S E B$ & $\beta$ & $p$ & $B$ & $S E B$ & $\beta$ & $p$ \\
\hline \multicolumn{9}{|l|}{ EP } \\
\hline absolutists versus evaluativists & -4.450 & 2.699 & -.250 & .106 & -.021 & .013 & -.260 & .121 \\
\hline multiplists versus evaluativists & -6.647 & 3.622 & -.266 & .073 & -.018 & .011 & -.238 & .132 \\
\hline Age & .451 & 1.408 & .048 & .750 & .003 & .008 & .083 & .692 \\
\hline PK & 2.916 & 1.947 & .232 & .141 & -.009 & .009 & -.207 & .304 \\
\hline
\end{tabular}

Note. EP: Epistemic perspective, PK: Prior-Knowledge. Epistemic perspective was represented by two dummy variables with evaluativists serving as the reference group. 
Table $4 b$

Summary of Multiple Regression Analysis on High Epistemic Processing on Credibility, using Epistemic Cognition, Prior Knowledge and Age as predictors, by Domain.

\begin{tabular}{|c|c|c|c|c|c|c|c|c|}
\hline \multirow[b]{2}{*}{ Variable } & \multicolumn{4}{|c|}{ History Domain } & \multicolumn{4}{|c|}{ Science Domain } \\
\hline & $B$ & $S E B$ & $\beta$ & $p$ & $B$ & $S E B$ & $\beta$ & $p$ \\
\hline \multicolumn{9}{|l|}{ EP } \\
\hline evaluativists versus absolutists & 2.898 & 2.712 & .149 & .290 & .021 & .013 & .281 & .121 \\
\hline multiplists versus absolutists & -2.949 & 3.422 & -.118 & .393 & .003 & .014 & .043 & .819 \\
\hline Age & 621 & 1.425 & .067 & .665 & .003 & .008 & .083 & .692 \\
\hline PK & 3.328 & 1.949 & .265 & .094 & -.009 & .009 & -.207 & .304 \\
\hline
\end{tabular}


Table 4c

Summary of Multiple Regression Analysis on High Epistemic Processing on Credibility, using Epistemic Cognition, Prior Knowledge and Age as predictors, by Domain.

\begin{tabular}{|c|c|c|c|c|c|c|c|c|}
\hline \multirow[b]{2}{*}{ Variable } & \multicolumn{4}{|c|}{ History Domain } & \multicolumn{4}{|c|}{ Science Domain } \\
\hline & $B$ & $S E B$ & $\beta$ & $p$ & $B$ & $S E B$ & $\beta$ & $p$ \\
\hline \multicolumn{9}{|l|}{ EP } \\
\hline evaluativists versus multiplists & 3.514 & 3.489 & .181 & .319 & .018 & .011 & .238 & .132 \\
\hline absolutists versus multiplists & -.048 & 3.281 & -.003 & .988 & -.003 & .014 & -.040 & .819 \\
\hline Age & .589 & 1.442 & .063 & .685 & .003 & .008 & .083 & .692 \\
\hline PK & 3.249 & 1.982 & .258 & .108 & -.009 & .009 & -.207 & .304 \\
\hline
\end{tabular}

Note. EP: Epistemic perspective, PK: Prior-Knowledge. Epistemic perspective was represented by two dummy variables with multiplists serving as the reference group. 
Table 5a

Summary of Multiple Regression Analysis on High Epistemic Processing of Evidence-claim Relation, using Epistemic Cognition, Prior Knowledge and Age as predictors, by Domain.

\begin{tabular}{|c|c|c|c|c|c|c|c|c|}
\hline \multirow[b]{2}{*}{ Variable } & \multirow[b]{2}{*}{$B$} & \multicolumn{3}{|c|}{ History Domain } & \multicolumn{4}{|c|}{ Science Domain } \\
\hline & & $S E B$ & $\beta$ & $p$ & $B$ & $S E B$ & $\beta$ & $p$ \\
\hline \multicolumn{9}{|l|}{ EP } \\
\hline absolutists versus evaluativists & -5.372 & 1.948 & -.359 & .008 & -2.700 & 1.780 & -.210 & .136 \\
\hline multiplists versus evaluativists & -7.541 & 2.614 & -.359 & .006 & -5.608 & 1.555 & -.471 & .001 \\
\hline Age & 2.369 & 1.016 & .303 & .024 & 4.059 & 1.050 & .674 & $<.001$ \\
\hline PK & 1.769 & 1.405 & .167 & .214 & -2.224 & 1.223 & -.304 & .075 \\
\hline
\end{tabular}

Note. EP: Epistemic perspective, PK: Prior-Knowledge. Epistemic perspective was represented by two dummy variables with evaluativists serving as the reference group. 
Table $5 b$

Summary of Multiple Regression Analysis on High Epistemic Processing of Evidence-claim Relation, using Epistemic Cognition,

Prior Knowledge and Age as predictors, by Domain.

\begin{tabular}{|c|c|c|c|c|c|c|c|c|}
\hline \multirow[b]{2}{*}{ Variable } & \multirow[b]{2}{*}{$B$} & \multicolumn{3}{|c|}{ History Domain } & \multirow[b]{2}{*}{$B$} & \multicolumn{2}{|c|}{ Science Domain } & \multirow[b]{2}{*}{$p$} \\
\hline & & $S E B$ & $\beta$ & $p$ & & $S E B$ & $\beta$ & \\
\hline \multicolumn{9}{|l|}{ EP } \\
\hline multiplists versus absolutists & -2.356 & 2.414 & -.112 & .334 & -2.908 & 1.861 & -.244 & .124 \\
\hline evaluativists versus absolutists & 5.551 & 1.913 & .339 & .006 & 2.700 & 1.780 & .227 & .136 \\
\hline Age & 2.543 & 1.005 & .325 & .015 & 4.059 & 1.050 & .674 & .000 \\
\hline PK & 2.033 & 1.375 & .192 & .146 & -2.224 & 1.223 & -.304 & .075 \\
\hline
\end{tabular}

Note. EP: Epistemic perspective, PK: Prior-Knowledge. Epistemic perspective was represented by two dummy variables with absolutists serving as the reference group. 
Table 5c

Summary of Multiple Regression Analysis on High Epistemic Processing of Evidence-claim Relation, using Epistemic Cognition,

Prior Knowledge and Age as predictors, by Domain.

\begin{tabular}{|c|c|c|c|c|c|c|c|c|}
\hline \multirow[b]{2}{*}{ Variable } & \multirow[b]{2}{*}{$B$} & \multicolumn{3}{|c|}{ History Domain } & \multirow[b]{2}{*}{$B$} & \multicolumn{2}{|c|}{ Science Domain } & \multirow[b]{2}{*}{$p$} \\
\hline & & $S E B$ & $\beta$ & $p$ & & $S E B$ & $\beta$ & \\
\hline \multicolumn{9}{|l|}{ EP } \\
\hline multiplists versus absolutists & 1.614 & 2.308 & .108 & .488 & 2.908 & 1.861 & .226 & .124 \\
\hline multiplists versus evaluativists & 7.202 & 2.454 & .440 & .005 & 5.608 & 1.555 & .471 & .001 \\
\hline Age & 2.590 & 1.015 & .331 & .014 & 4.059 & 1.050 & .674 & .000 \\
\hline PK & 2.114 & 1.394 & .200 & .136 & -2.224 & 1.223 & -.304 & .075 \\
\hline
\end{tabular}

Note. EP: Epistemic perspective, PK: Prior-Knowledge. Epistemic perspective was represented by two dummy variables with multiplists serving as the reference group. 